Reprinted from Nature, Vol. 195, No. 4845, pp. 939-943, September 8, 1962)

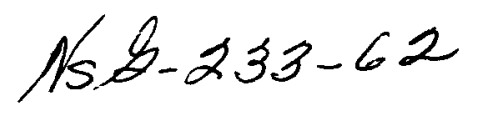

\title{
GEOMAGNETICALLY TRAPPED RADIATION PRODUCED BY A HIGH-ALTITUDE NUCLEAR EXPLOSION ON JULY 9, 1962
}

\author{
By Dr. B. J. O'BRIEN, Dr. C. D. LAUGHLIN and \\ Prof. J. A. VAN ALLEN
}

Department of Physics and Astronomy, State University of Jowa, lowa City

T

TIS is a preliminary report of investigations made with the satellite Injun $I$ of the artificial radiation belt produced by a nuclear device recently exploded at a high altitude. The officially available information on this burst is contained in the international $A G I W A R N$ message of July 9,1962 , ". . . a megaton yield range device was detonated in the ionosphere at an altitude of hundreds of kilometers in the vicinity of Johnston Island in the Pacific at 0900 U.T. on July 9, 1962"' The goographic position of Johnston Island is $16.7^{\circ}$ N.. $190.5^{\circ} \mathrm{E}$.

For every kiloton fission explosion in the device, there were produced about $10^{23}$ fission nuclei the radioactivy decay of which yielded some $5 \times 10^{23}$ electrons ${ }^{1}$ having, presumably, a differential number energy spectrum approximated by $3.88 \exp (-0.575 \mathrm{E}$ $-0.055 E^{2}$ ), for the range $1 \leq E \leq 7 \mathrm{MeV}$, where $E$ is the $\beta$-ray energy in $\mathrm{MeV}$, and the spectral expression is in units of $\beta$-rays per fission per $\mathrm{MeV}$ (ref. 2). Some of these electrons were injected at such pitch angles to the geomagnetic fiold vector that they were temporarily trapped, oxecuting oscillatory motion in latitude along magnetic field lines and drifting eastward in longitude to form an artificial radiation belt encircling the Earth. This is the first reported case of a significant, artificial injection of durably trapped particles into the geomagnetic field since the Argus tests of $1958^{3,4}$.

\section{Experimental Details}

The present article is based on observations made with the State University of Iowa satellite Injun I (1961 omicron 2) which was designed for study of the naturally occurring radiation belts. It was launched at 0423 U.r. on July 29,1961 , into an orbit with apogee altitude $1,010 \mathrm{~km}$, perigee altitude $890 \mathrm{~km}$, inclination $67^{\circ}$ and period $104 \mathrm{~min}$. The satellite 
Table 1. Particles Detectable by Dirfat Penetration

Detector 1

Detector 2

Detector 3

$$
\begin{aligned}
& \text { Electrons } \\
& \text { Protous } \\
& E^{>}>500 \mathrm{keV} \\
& E \geq 45 \mathrm{MeV} \\
& E>6 \mathrm{MeV} \\
& \left(\begin{array}{c}
E^{>} \stackrel{\sim}{\sim} \mathrm{MeV} \\
\text { order of } 1 \text { per cent efticiency }
\end{array}\right) \\
& 1 \cdot 5 \leqslant \boldsymbol{L}^{\dagger} \leqslant 15 \mathrm{MeV}
\end{aligned}
$$

transmits real-time data from its array of radiation detectors on command from several ground stations, distributed around the world ${ }^{5}$. For the present purposes the telemetry data from the following stations are of significance: Quito, Lima, Salisbury (Southern Rhodesia), Iowa City and several Pacific Island stations.

There are three particle detectors on Injun $I$ the outputs of which are used in this preliminary investigation, but in a more detailed analysis now being undertaken another seven detectors will give useful information.

Detector 1. An end-window Geiger tube (Anton type 213) with shielding of $1.2 \mathrm{mg} \mathrm{cm}^{-2}$ over a conical field of angular diameter $30^{\circ}$, and $4.5 \mathrm{~g} \mathrm{~cm}^{-2}$ of lead elsewhere (L. Frank, private communication).

Detector 2. A similar Geiger tubo complotoly encased in a shield of $3.5 \mathrm{~g} \mathrm{~cm}^{-2}$ of lead and a further $1 \mathrm{~g} \mathrm{~cm}^{-2}$ of stainless steel.

Detector 3. A $p-n$ junction detector with an electronic bias of $1 \mathrm{MeV}$ and a conical field of view of angular diameter $30^{\circ}$ shielded by $2 \mathrm{mg} \mathrm{cm}^{-2}$. Shielding elsewhere is $\geqslant 3 \mathrm{~g} \mathrm{~cm}^{-2}$ (G. F. Pieper, private communication).

An abridged summary of properties of the detectors is given in Tablo 1 .

It is tentatively estimated that the responso of Detector 2 to the fission electron spectrum is due dominantly to direct penetrations of the shield by energetic electrons $(E \geq 6 \mathrm{MeV})$ and not to the bremsstrahlung of the more abundant non-penetrating ones. This estimate is being re-examined by further laboratory examination. The following investigations of the spatial extent and the time-decay of the artificial radiation zone are essentially independent of the validity of the foregoing working hypothesis.

Detectors 1 and 3 are directional, and their response depends on the angle at which they point with respect to the magnetic field vector. Both have associated background dotectors which measure any penetrating contaminating radiation. Detector 2 is an omnidirectional detector and provides the simplest means of mapping out the natural and artificial radiation zones, since its response is independent of the orientation of the satellite. 
A fuller description of the Injun $I$ system is given in the previously cited paper of O'Brien et al. ${ }^{5}$.

\section{Some General Considerations on Geomagnetic Trapping}

The dynamics of geomagnetically trapped particlos as recently reviewed by Van Allen ${ }^{6}$ are applicable to the particles injected by the Johnston Island burst. In particular, it is necessary to use the fully detailed properties of the real geomagnetic field in order to make a systematic study of spatial distribution and time-decay. The co-ordinate system of McIlwain ${ }^{7}$ is used here to replace the three geographic co-ordinates longitude, latitude and altitude with the two 'natural' geomagnetic co-ordinates $B$ and $L$.

The value of $L$ is constant for a given line of magnetic force along which a charged particle oseillates in latitude. It also labels a unique magnetic shell on which the particle drifts in longitude. Numerically, $L$ is such that if the geomagnetic field were that due to a simple dipole, then the equatorial radial distance from the centre of the Earth to a given magnetic shell would be $L$ Earth radii. The strength of the magnetic field at a point in space is $B$ gauss.

In a time-stationary state, at any two points in space with the same values of $B$ and $L$ the intensity of trapped particles is the same. In the equatorial regions at Injun altitudes of $\sim 1,000 \mathrm{~km}$ there are trapped the particles of the inner radiation zone which is relatively stable with time. During the first year of observations by Injun I, some ten million measurements were made in the inner zone. Hence the counting-rates of all detectors due to naturally occurring trapped particles are well known and are tabulated in $B, L$ co-ordinates. The intensities of the natural inner radiation zone as it was before the burst are used in this article as reference-levels. As will be seen in the following, the intensities due to the artificially injected particles are much greater than normal intensities in the inner zone, especially at the lower altitudes. This fact must be clearly recognized by those conducting flights in this region during 1962. Furthermore, because of it, we do not treat in this article any possible effects of the burst on the former inner zone particles themselves.

The dependence on $B$ and $L$ of particle intensity in the inner zone is shown in Figs. 5 and 6 of ref. 7 using data from detectors on the satellite Explorer $I V$, which also observed the artificial belts of electrons resulting from the three Argus bursts. The shielded Geiger tube on Explore' $I V$ had shielding significantly 


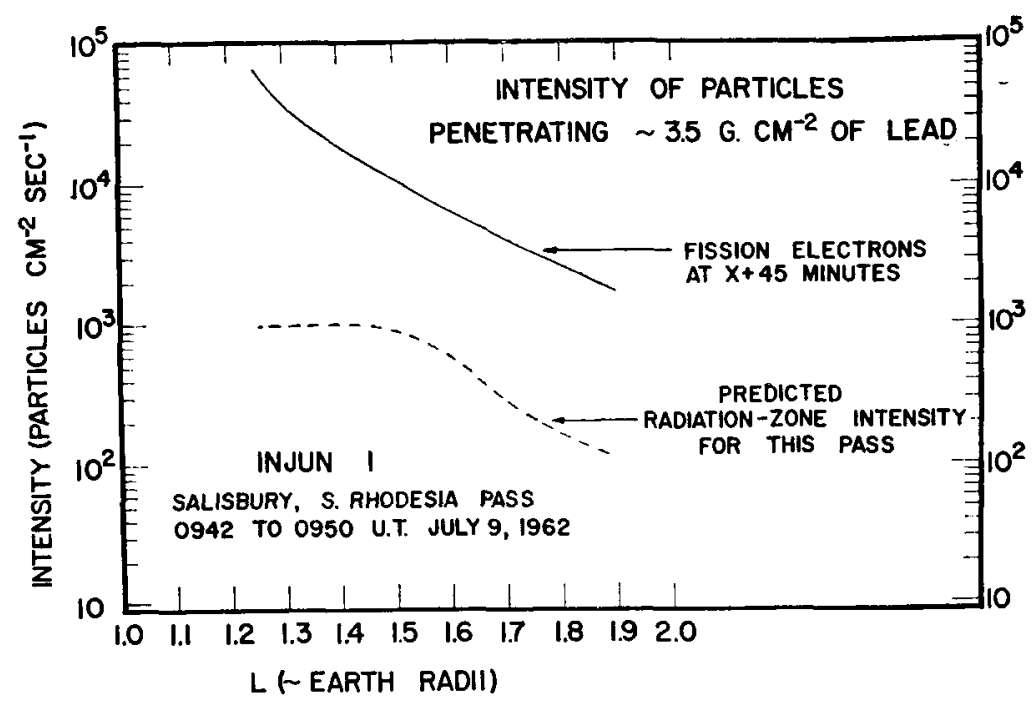

Fig. 1. Comparison of the intensity of the new artificial raliation belt and the natural inuer radiation belt measured with betector 2 in the same region over southern Rlodesia. In calculating the intensity, the assumption is mide that the detector is efficiently counting only tission electrons with $F^{>} \sim 6 \mathrm{MeV}$ (see text)

less than that of Detector 2 above and had an effective area about five times larger than that of Detector 2 .

Before the Johnston Island burst, the countingrates of Detectors 1,2 and 3 in the equatorial region were dominantly due to inner zone electrons, protons and protons, respectively. After the ovent, there are three possible contributions: $(a)$ from penetrating electrons from fission decay; (b) from decay products of neutrons produced in the explosion; (c) from a redistribution in space of naturally occurring trapped particles. The observed spectrum in equatorial regions is in crude accordance with the assumption that the dominant contribution is from penetrating fission-decay electrons.

As to contribution (b), according to Latter, Herbst and Wutson ${ }^{2}$ about one neutron per fission escapes from a nuclear burst. The subsequent neutron-decay injection process yields a more-or-less uniform 'source function' of electrons with $E<780 \mathrm{k} \theta \mathrm{V}$ and energetic protons mostly with $E \sim 1 \mathrm{MeV}$ over an immense region of space. By contrast, there is a comparable number of fission-decay electrons, which come from a localized 'source function' and are much more energetic and penetrating. In this article wo consider only the equatorial regions where the localized 'source function' of fission-decay electrons is large. 
In this region it can be shown that noutron-decay products would have had less effect on Detectors 1 . 2 and 3 than would the naturally occurring particles of the inner radiation zone.

As to contribution (c), the pre-burst peak countingrate of Detector 2 at Injun altitude was only about 700 counts $\mathrm{sec}^{-1}$, and its extrapolated rate in the heart of the inner zone was only about 1,200 counts $\mathrm{sec}^{-1}$. Yet it reached rates of more than 11,000 counts sec $^{-1}$ after the burst, and it seems clear that such rates could not have resulted from any reasonable redistribution of naturally oceurring trapped particles.

Therefore, it is tentatively assumed that the dominant contribution to Detectors 1,2 and 3 in equatorial regions after the burst was from penetrating electrons from fission decay. The validity of this assumption and its applicability at higher latitudes are being further examined.

\section{Eariy Effects of the Explosion}

Injun $I$ was at longitude $224^{\circ}$ E., latitude $36^{\circ} \mathrm{N}$. and altitude $886 \mathrm{~km}$ and was moving north-east at the nominal explosion time of 0900 V.T. on July 9 , 1962. We call this time $t=X$ h. Injun was not transmitting at the time.

Injun was transmitting over Salisbury. Southern Rhodesia, at $X+4 \tilde{3}$ min. Thus it raced the slow electrons eastward around the world, and only electrons with energy $E \geq 500 \mathrm{keV}$ would have drifted around from the explosion to Salisbury by the time of the pass (Figs 1.2 and 1.3 of ref. 6 for longitudinal drift period as a function of energy).

By $\mathbf{X}+45$ min there was a shell of trapped electrons extending out to at least $L \sim 1.9$ over South Africa (Fig. 1).

Table 2. Early Meastremenzs of Particle INTENsities (assumin G THAT ONLY EIECTRONS ARE PRESENT)

\begin{tabular}{|c|c|c|c|}
\hline (em & $\begin{array}{c}\text { Detertor } 1 \\
\text { Intensity } \\
\text { elcctrons } \\
E \geqslant 40 \mathrm{keV} \\
\text { particles } \\
\mathrm{m}^{2} \text { sec sterad) }\end{array}$ & $\begin{array}{c}\text { Detector } 2 \\
\text { Intensity } \\
\text { clectrons } \\
E \geqslant 6 \text { Afel } \\
\text { particles } \\
\text { (cm ser) })^{-1}\end{array}$ & $\begin{array}{c}\text { Detector } 3 \\
\text { Intensity } \\
\text { electrons } \\
E \geqslant 1 \mathrm{MeV} \\
\text { particles } \\
\text { (cm }^{2} \text { sec sterad) }\end{array}$ \\
\hline $\begin{array}{l}X+45 \text { min } \\
\text { (a) Xormal to } \vec{F} \\
\text { at } L=1 \cdot 32\end{array}$ & $3 \times 10^{2}$ & $3 . \tilde{5} \times 10^{4}$ & $\begin{array}{c}\sim 10^{7} \text { (order of } \\
\text { magnitude } \\
\text { estimate) }\end{array}$ \\
\hline $\begin{array}{l}\text { (b) Peak intensity } \\
\text { at } L=\mathbf{1 . 2 6}\end{array}$ & - & $\left(\right.$ see ${ }^{6.5 \times 10^{4}}$ Fig. $)$ & 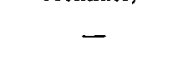 \\
\hline $\begin{array}{l}x+100 \text { min } \\
\text { (a) Normal to } \vec{B} \\
\text { at } L=1 \cdot 35\end{array}$ & $2 \times 10^{4}$ & $2 \times 10^{2}$ & 一 \\
\hline $\begin{array}{l}\text { (b) Peak intensity } \\
\text { at } L=1 \cdot 13\end{array}$ & - & $2.5 \times 10^{2}$ & - \\
\hline
\end{tabular}


The satellite was also transmitting over Johnston Island at $X+100 \mathrm{~min}$ and so it arrived there ahead of any eloctrons with energy $E \leqslant 500 \mathrm{keV}$ which were drifting around the world, but it would have started to overtake lower-energy electrons after passing Johnston Island.

In these two passes, the directional Detectors 1 and 3 were not pointing at right angles to the magnetic field at the times when the omnidirectional Detector 2 indicated that the particle intensity was at its maximum. In the intensity measurements listed in Table 2 we quote :

(a) Intensitios measured by Ietectors 1 and 3 when they were pointert perpendicular to the magnetic field, that is. when they wero measuring the peak directional intensity of particles at that place and time. The intensity measured by the omnidirectional Detector 2 at the same place and time is also given. From such data the electron energy spectra may be obtained. Then:

(b) The peak intensity observed by Detector 2 during the samo pass is listed. 'The spectral data of (a) may then be nommalized to the peak intensity of

(b) if it bo assumed that the electron spectrum is the

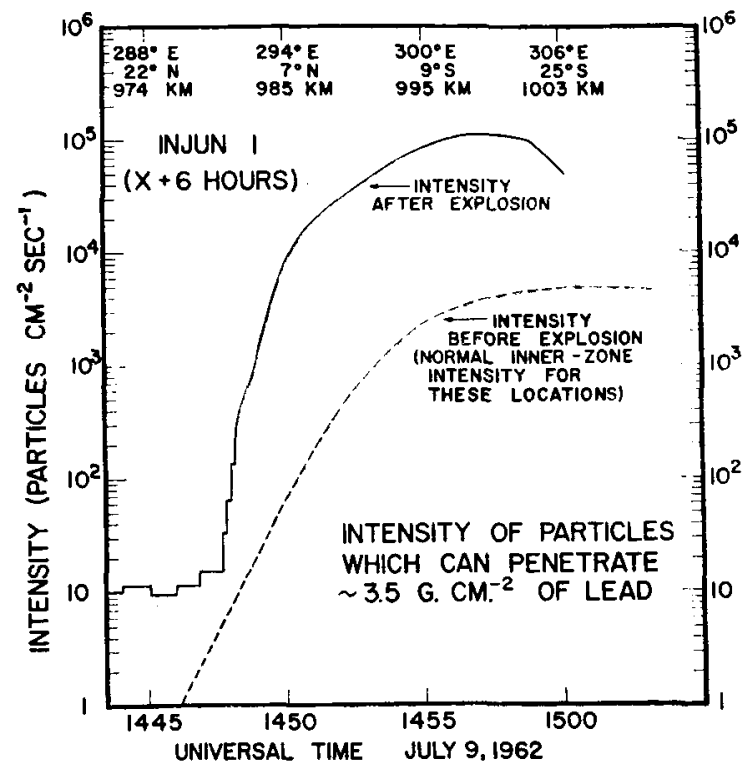

TIME AFTER EXPLOSION 6 HOURS $\uparrow$

Fig. \&. Comparison of the observed particle intensity after the explosion with the normal zone intensity for a pass over South America. The locations shown are in geographic co-ordinates 


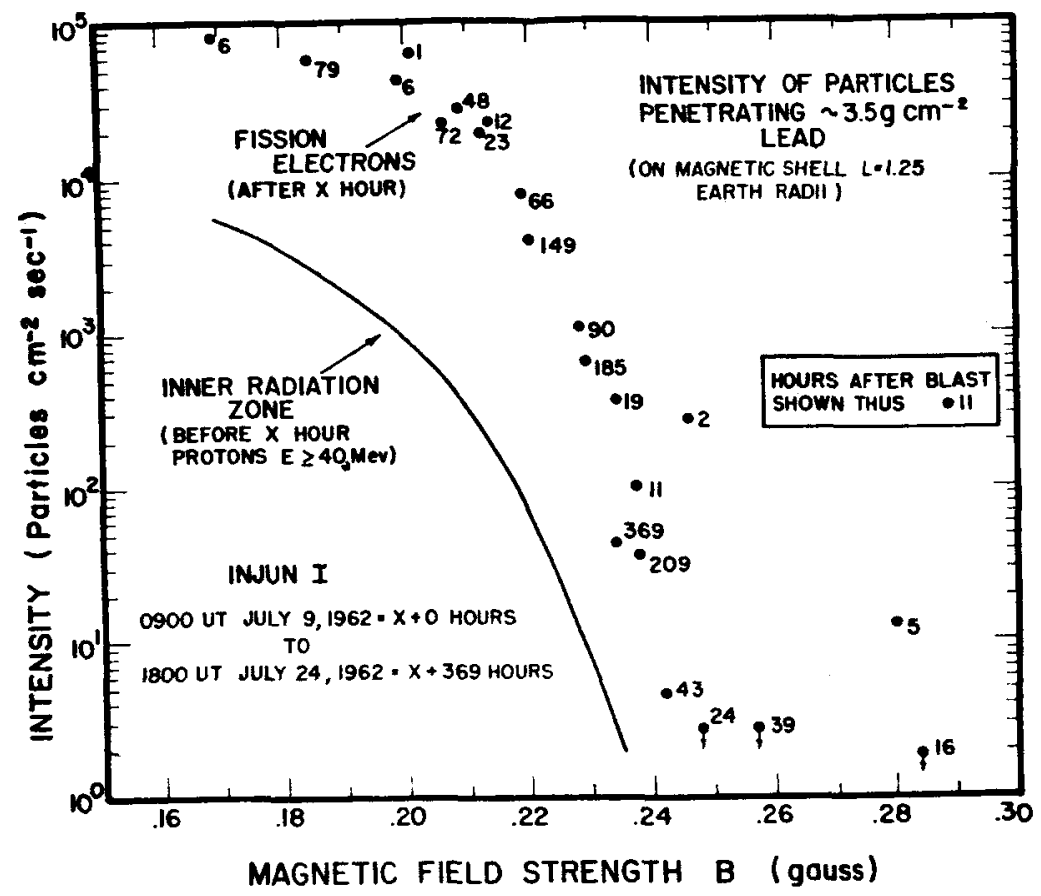

Fig. 3. Variation of particle intensity on the magnetic shell $L=1 \cdot 25$ Earth radii as a function of magnetic field strength $(B)$ aud the elipsed tine since the explosion. The intensity decreases most rapidly at large values of $B$, that is, at low altitudes. A measurement obtained very recently and not plotted was an intensity of $\left(4 \cdot 3 \times 10^{4}\right)$ particles $\mathrm{cm}^{-2} \mathrm{sec}^{-1}$ at $B=0.192$ gauss at $(X+459) \mathrm{h}$. Note that this was after the moderate magnetic storm of $\mathbf{J}$ uly 26

same at the two locations. This matter is being investigated in detail.

The lower intensity over Johnston Island than over Salisbury is due presumably to the fact that a given geographical altitude over Johnston is equivalent, geomagnetically, to one several hundred kilometres lower over Salisbury. The decay of intensity in both the short term and the long term is dominated by the atmospheric density at the longitude at which the mirror points of particles are deepest in the atmosphere (see later). The dependence of particle intensity at a given value of $L$ and at low altitudes is an extremely strong function of $B$ for both the natural and artificial radiation zones for $L_{\sim}^{<} 1 \cdot 5$. For example, in the normal inner radiation zone the particle intensity changes by an order of magnitude over an altitude change of less than $100 \mathrm{~km}$.

In Fig. 1, the enhancement after the explosion of 


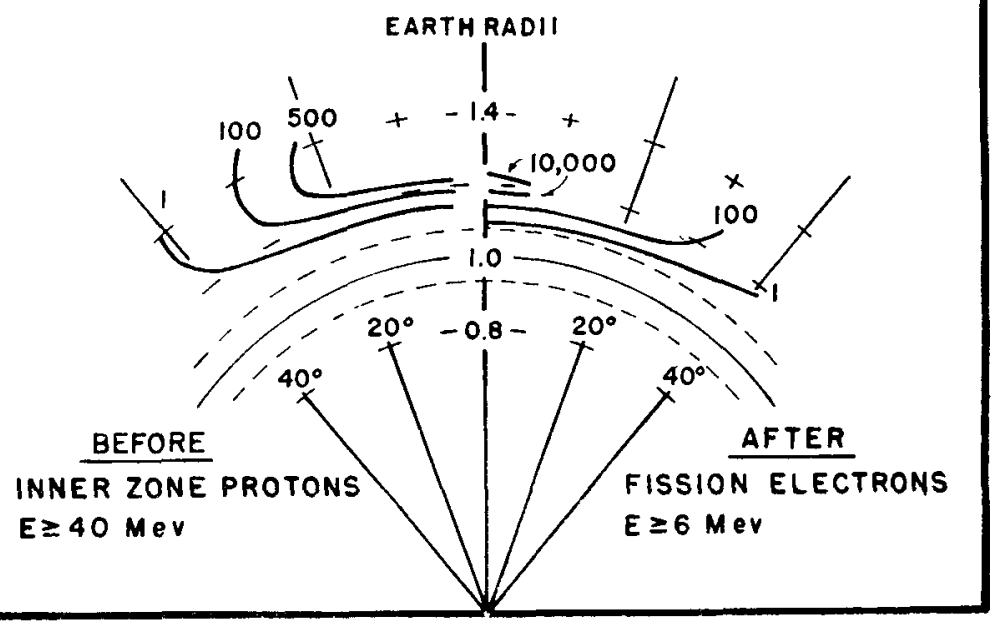

Fig. 4. Contours of constant counting-rate of Detector in in the polar co-ordinate system discussed by Mellwain (ref. T) for the normat inner radiation zone on the left and for the intificial rialiation zone on the right about $6 \mathrm{~h}$ after the explosion. The dashed lines indicate the maxinum excursions of the Earth's surface in these co-ordinates. An omnidirectionil intensity of about nine penetrating particles $\mathrm{cm}^{-2} \mathrm{sec}^{-1}$ will cause 1 count see $^{-1}$ in the detector

the intensity of particles which could penetrate more than $3.5 \alpha \mathrm{cm}^{-2}$ of leat is cloarly shown for Salisbury at $\mathrm{X}+45 \mathrm{~min}$. The enhancement is about one

- humdred-fold around $L \sim 1 \cdot 2$. Over Johnston Island the cenanerment neal the peak of the artificial zone around $L \sim 1.13$ was nore than one thousand-fold.

From data such as those shown in Figs. 1. 2. 3 and 4. it is estinated that there wore of the order of $10^{24}$ freshly injocted and trapped electrons of energy $E_{\sim}^{2} 1,500 \mathrm{k} V \mathrm{~V}$ in the greomagnetic field at $X+1 \mathrm{~h}$. The total mass of theso particlos which have created this intense rarliation bolt is therefore only of order $1 \mathrm{mg}$.

\section{Long-Term Observations}

There is considerable interest in a detailed observational study of the time decay of the artificial rarliation bolt over a perior spanning both magnetically quiet and magnetically disturbed conditions. Such a study is in progress. The moderate magnetic 
storn of July 26, 1962, did not have any pronounced effect, but further studics with other storms must bo made. The results may be expected to bo of value in determining the loss rates of naturally injocted particles and hence the source strength for such particles. Hopofully, some of the uncortainty concerning the orien of the inner zone can be dispolled.

In this preliminary report. the rate of loss of electrons of $E^{2} \approx \mathrm{MoV}$ only is considered and this, briefly. Data from a single pass are shown in Fig. 2. From many such passos, the particlo intensity on a given magnetic shell, say $L=1 \cdot 2.5$ as in $\mathrm{Fig}, 3$, is plotted as a function of $B$. The time-dependence of intensity at chosen sets of values of $B$ and $L$ can be examined with the holp of such rraphs. For the magnetic shell $L=1 \cdot 25$, the minimum altitudes at which $B=0.20,0.22$ and 0.25 gauss aro rospectively about 540, 350 and $140 \mathrm{~km}$. Henco from Fig. 3 it appears that, for this magnetic sholl and this phenomenon, the intensity of electrons with $E_{\sim 6}^{>0}$ $\mathrm{MeV}$ which mirrorod as low or lower than $140-\mathrm{km}$ altitude became negligible (that is, becamo undetectable with this instrmment) within a few houls. Tho intensity of those mirroring at or below $350 \mathrm{~km}$ was greatly reduced within a few veeks. whilo high intensities of those mirroring above 500 kilometers will persist for months. A yroper treatment of tho problem using transport thoory and the combined results from all detectors is being undortaken.

\section{Comparison with Argus Series}

Three fission devices of about 1 kiloton yiold were detonated by the United States at high altiturles in August-September 1958. The rosulting artificinl radiation belts were less than 0.1 Earth radius thick at the equator and had poak intensitics at about $L=1 \cdot 7,2 \cdot 1$ and $2 \cdot 2$ Larth radii respectively ${ }^{\prime}$.

A proliminary comparison of tho shitded Geigor tube clata (Explorer $I V$ ) on tho Argus sholls with the present data from Detector 2 in $L n j u n$ shows that the initial intensity in the Johnston Island shell was of the order of one thousand times as great as that observed by Explorer I $V$ on the Argus sholls. Bocauso Explorer IV sampled the Argus sholls only at altitudos less than about $2,000 \mathrm{~km}$ and so considerably below their equatorial altitudes, it did not measure the peak Argus intonsities. Howover, Injun samples tho artificial radiation belt near the equator and hence near the peak intensities. A detailed comparison of the phenomena is being made. 


\section{Discussion}

It appears likely that the electrons artificially injected by the Johnston Island burst will continue to be present in measurable numbers for many months on the higher-altitude shells.

As a consequence, the electron spectrum and intensity at high altitudes for magnetic shells with $L_{\sim}^{<2}$ will differ from those of the previously studied inner radiation zone for some months. A short tabulation in terms of $B$ and $L$ of the electron intensities now in this region has been prepared and circulated privately.

Perhaps the best overall view of the artificial radiation belt as available at present is obtained by examination of Fig. 4. One should note in particular the low altitudes to which the belt extends, and the counting-rates very much higher than those observed in the natural inner belt with the same detector. For comparison also, a similar detector has a peak counting-rate of only about 100 counts $\sec ^{-1}$ in the heart of the outer radiation zone.

Invaluable telemetry reception at equatorial stations was obtained through the co-operation of Roger Tetrick of the Goddard Space Flight Centre, Rolf Dyce and George Johnson of the Stanford Research Institute and W. S. Carey of Salisbury, Southern Rhodesia.

This work was supported in part by the Office of Naval Ressarch under contract N9onr93803 and by the National Aeronauties and Space Administration under grant Nos. $\$ 233-62$.

1 Latter, R., Herbst, R. F., and Watson, K. M., Ann. Rev. Nuclear Sci., 11, 371 (1961).

sarter, R. E., Reines, F., Wagner, J. J., and Wyman, M. E., Phys. Rer., 113, 280 (1959).

Christofilos, N. C., J. Geophys. Res., 64, 869 (1959).

- Van Allen, J. A., Mellwain, C, E., and Ludwig, G. H., J. Geophys. Res., 64, 877 (1959).

- O'Brien, B. J., Laughlin, C. D., Van Allen, J. A., and Frank, L. A., J. Geophys. Res., 67, 1209 (1962).

- Van Allen, J. A., Trans. Intern. Astro. Union (in the press).

'McIlwain, C. E., J. Geophys. Kes., 66, 3681 (1961). 